\title{
Primo Levi além da literatura: um intelectual engajado
}

\author{
Aislan Camargo Maciera \\ Universidade de São Paulo \\ aislan@usp.br \\ Helena Bressan Carminati \\ Universidade Federal de Santa Catarina \\ helenabcarminati@gmail.com
}

RESUMO: Pensando em situações que há muito percorrem nosso cotidiano, propõe-se aqui um olhar que, partindo do passado, estende-se ao presente. São temas ainda urgentes e que encontram no escritor italiano Primo Levi (19191987), uma voz que ultrapassa a experiência do Lager e que se preocupa com as questões do mundo. Trazendo, então, como pano de fundo a sua produção literária, propõe-se perceber o autor para além de suas narrativas, contos ou poemas, sem deixar, certamente, de considerá-los. A experiência de Auschwitz, que se tornou matéria de sua escrita, foi também aquela que lhe despertou, de modo latente, a observação atenta da vida ao seu redor, a partir do olhar do químico, ofício que primeiro exerceu. Após a publicação de grande parte de seus livros, Levi, já aposentado da indústria química, passa a colaborar mais frequentemente com vários jornais italianos, escrevendo importantes artigos e ensaios sobre os mais diversos assuntos. Desde prefácios a comentários sobre o contexto político italiano da época, ocupando-se dos animais, de cultura e das palavras, passa uma vida percebendo e elaborando o mundo visível e invisível ao seu redor. Desse modo, nas páginas que se seguem, pretende-se trazer a figura do escritor que, embora conhecido por sua literatura, consolidou-se como intelectual engajado, ocupando espaços para estabelecer diálogos possíveis com os contextos contemporâneos. Além disso, apresentar-se-á a tradução inédita de uma entrevista concedida pelo autor em 1985, intitulada Primo Levi: o racismo volta nu e cru.

Palavras-chave: Literatura italiana. Primo Levi. Escritor engajado. Tradução. Racismo.

ABSTRACT: Pensando a situazioni che da tempo attraversano la nostra quotidianità, si propone uno sguardo che, partendo dal passato, si estende fino al presente. Sono temi ancora urgenti e che incontrano nello scrittore italiano Primo Levi (1919-1987), una voce che va oltre l'esperienza del Lager e che si occupa delle questioni del mondo. Quindi, presentando la sua produzione letteraria come sfondo, si intende percepire lo scrittore al di là dei suoi romanzi, racconti o poesie, senza lasciare di considerarli. L'esperienza di Auschwitz, che divenne oggetto della sua scrittura, fu anche quella che lo risvegliò, in modo 


\section{Primo Levi além da literatura: um intelectual engajado \\ Aislan Camargo Maciera \\ Helena Bressan Carminati}

latente, un'attenta osservazione della vita che lo circondava, dallo sguardo del chimico, ufficio che per prima esercitò. Dopo la pubblicazione di buona parte dei suoi libri, Levi, già in pensione dall'industria chimica, inizia a collaborare più frequentemente con diversi quotidiani italiani, scrivendo importanti articoli e saggi sui temi più diversificati. Dalle prefazioni ai commenti sul contesto politico italiano dell'epoca, occupandosi degli animali, della cultura e delle parole, trascorre una vita a percepire ed elaborare il mondo visibile e invisibile che lo circonda. In questo modo, nelle pagine che seguono, si intende riportare una figura dello scrittore che, pur noto per la sua letteratura, si è consolidato come intellettuale impegnato, occupando spazi per stabilire possibili dialoghi con i contesti contemporanei. Verrà inoltre presentata una traduzione inedita di un'intervista rilasciata dall'autore nel 1985, dal titolo Primo Levi: il razzismo torna nudo e crudo.

Parole chiave: Letteratura italiana. Primo Levi. Scrittore impegnato. Traduzione. Razzismo.

ABSTRACT: Thinking of situations that have been going on in our daily lives for a long time, we propose in this article a look into them that, starting from the past, extends to the present. These are still urgent topics and in the work of the Italian writer Primo Levi (1919-1987), they find a voice that goes beyond Lager's experience and that is concerned with the issues of the world. Bringing to the discussion his literary production as a backdrop, we propose to perceive the author beyond his narratives, tales or poems, without failing to consider them. Auschwitz's experience, which became the subject of his writing, was also the one that awakened him, in a latent way, an attentive observation of the life around him, from the look of the chemist, a profession he first exercised. After the publication of a large part of his books, Levi, already retired from the chemical industry, starts to collaborate more frequently with several Italian newspapers, writing important articles and essays on the most diverse subjects. From prefaces to comments on the Italian political context at the time, dealing with animals, culture and words, he spent a lifetime perceiving and elaborating the visible and invisible world around you. In this way, in the pages that follow, we intend to bring a figure of the writer who, although known for his literature, consolidated himself as an engaged intellectual, occupying spaces to establish possible dialogues with contemporary contexts. In addition, an unprecedented translation of an interview given by the author in 1985, entitled Primo Levi, will be presented: racism returns naked and raw.

Keywords: Italian literature. Primo Levi. Engaged writer. Translation. Racism. 


\section{Primo Levi além da literatura: um intelectual engajado \\ Aislan Camargo Maciera \\ Helena Bressan Carminati}

\section{Introdução}

Os dias do passado parecem não ter fim. São acontecimentos históricos e sociais que ultrapassam a linha do tempo e se mantêm firme, numa invasão quase diária de nossas vidas. O cotidiano moderno se vê acorrentado a uma espécie de eterno passado que não passa. De imagens e cenas que invadem as telas de nossos dispositivos e nos relembram comportamentos que, embora temporalmente distantes, retornam em outras vestes. Ameaças ao próprio homem e, ao que se discutiu após certos acontecimentos do século passado, que voltam e fazem do presente um espaço de reverberações que, embora novo, carrega traços problemáticos de pensamentos bastante questionáveis.

Assim, em um movimento de olhar o passado com a distância necessária e, por vezes, difícil, podemos recorrer à literatura como uma linguagem que tenta lidar e compreender os fatos, trazendo-os para o plano da ficção. Lembrando, então, de autores que fizeram de seus escritos um espaço de reflexão sobre o real e os contextos do cotidiano, o nome de Primo Levi (19191987) torna-se um imperativo. Levi, judeu italiano, conhecido mundialmente por sua literatura de testemunho, foi uma das grandes vozes do século XX. No entanto, apesar de sua vasta produção literária, de narrativas a poemas, nosso olhar estará voltado para outra faceta de seus escritos, igualmente profícua e importante: a sua obra ensaística. O que nos interessa, neste momento, é pensar em Primo Levi como um escritor empenhado em problematizar e elaborar reflexões sobre as mais variadas questões sociais, e não apenas no âmbito da literatura. Seu "desejo constante de não permanecer na superfície das coisas" e de conhecer profundamente os mecanismos que movem o homem e a natureza são elementos fundamentais na sua formação como escritor e intelectual.

Para isso, seria inevitável apresentar suas narrativas, contudo, as exploraremos como pano de fundo e força motriz de um trabalho engajado que se estende para além dos livros publicados, e se demonstra no grande número 


\section{Primo Levi além da literatura: um intelectual engajado \\ Aislan Camargo Maciera \\ Helena Bressan Carminati}

de artigos que o autor escreveu entre os anos 1950 e 1980. Apresentaremos, então, algumas considerações sobre essa obra ensaística e, em um segundo momento, a tradução inédita para o português de uma entrevista concedida por Levi em 1985, intitulada Primo Levi: o racismo volta nu e cru, que integra o terceiro volume da edição das obras completas do autor - Opere complete III: conversazioni, interviste, dichiaraz̧ioni. Tal entrevista servirá como uma ilustração a um tema de fundamental importância na história da humanidade e da vida em sociedade: o racismo. Além disso, dialoga com um artigo de 1979, intitulado Intolerância racial, e ambas as referências são de suma importância para evidenciar o papel de Primo Levi para além do literário, sem deixar, é claro, de contemplá-lo.

\section{De Auschwitz ao empenho para além do literário}

Aos 25 anos de idade, após ter sido preso pela milícia fascista, em dezembro de 1943, e levado para um campo de transição na cidade italiana de Fossoli, Primo Levi foi deportado para um dos campos de concentração e extermínio do complexo de Auschwitz, onde permaneceu por quase um ano, até a libertação pelos soviéticos. Passando, então, pelo trauma e pela dor daqueles dias, entre fevereiro de 1944 e janeiro de 1945, já durante a odisseia de retorno para casa, na viagem de trem de Verona a Turim, sua cidade natal, o exprisioneiro demonstrara certa necessidade em compartilhar sua experiência:

\footnotetext{
Escrever havia se tornado para mim uma necessidade, para me libertar de um peso que carregava comigo: muitos daqueles que sobreviveram em Auschwitz, sobreviveram exatamente para contar. E eu, antes de escrever, contei aquelas histórias. Falava com todos, nos trens, nos bondes, logo que conseguia atrair a atenção de alguém. [...] Sentia, ainda mais que no Lager, a ofensa que havia sofrido, e entendia que o único modo de me salvar era contar. A escrita é um ato de libertação: se não tivesse escrito, provavelmente teria permanecido como um condenado na terra. (LEVI, 2018, p. 122, tradução nossa)
}

Demonstrando, portanto, uma necessidade bastante aflorada pela partilha e pelo diálogo, Levi, químico por formação, decidiu confrontar-se com a página 
em branco e vivenciar um processo de experimentação e trabalho com a linguagem. Transformou em escrita sua vida dos últimos meses, dando os contornos daquela que seria sua obra de estreia: Se questo è un nomo, publicada na Itália em 1947. Suas páginas, nesse sentido, carregam e respingam a urgência e a necessidade de compartilhar a experiência da Guerra.

Após a publicação de seu livro, Levi sempre destacou que a necessidade de narrar a sua experiência foi o impulso que o levou ao gesto da escrita. As palavras, como num grande impulso precisavam desaguar em outros afluentes que não fosse o rio principal, aquele espaço onde ficariam restritas a um mesmo lugar. Escrever, desse modo, representou uma fuga, um escape, para que outras pessoas pudessem também conhecer aquela experiência, e de algum modo, tornarem-se testemunhas. Contudo, a publicação de Se questo è un nomo pela Francesco De Silva, única editora que aceitou publicá-lo, foi pouco apreciada, ficando restrita ao âmbito intelectual de Turim. Das 2.500 cópias do livro, apenas 1.000 foram vendidas, enquanto as outras acabaram se perdendo em uma enchente que atingiu o depósito da editora em Florença.

O período imediatamente posterior ao fim do conflito mundial não apresentava, de fato, um ambiente favorável à difusão daquelas memórias. Mas Levi queria contar. Era uma necessidade quase fisiológica - "Tornare, mangiare, raccontare" -, que ia além do desejo; era uma urgência nascida na mente do jovem químico ainda no Lager. Em uma de suas entrevistas mais conhecidas, concedida ao jornalista Luigi Silori, em 1963 - também ex-prisioneiro de um dos campos de concentração e extermínio - Levi declara (LEVI, 2018, p. 14, tradução nossa) que havia escrito o primeiro livro "porque não poderia não escrevê-lo". E complementa: "Recordo com precisão que, desde o tempo em que estava no campo de concentração, ao lado do desejo profundo e feroz de sobreviver, vivia um outro desejo preciso: voltar para casa para escrever essas coisas que escrevi". 


\section{Primo Levi além da literatura: um intelectual engajado \\ Aislan Camargo Maciera \\ Helena Bressan Carminati}

Em 1955, dez anos após o final da Segunda Guerra, uma mostra dedicada à Resistência no Piemonte foi aberta no Palazzo Madama, em Turim. Organizada pelo Instituto Histórico da Resistência e pela administração municipal, o evento tinha a intenção de rememorar, após pouco mais de uma década, como havia surgido e se desenvolvido a Resistência aos nazifascistas após 8 de setembro de 1943, data da entrada em vigor do armistício assinado pelo governo italiano. A exposição sobre a Resistência, dentre outros materiais, apresentava ao público documentos, recortes de jornais, fotografias e um número especial da revista Torino, dedicado à memória dos partigiani que lutaram contra a ocupação nazista e os fascistas colaboracionistas da República de Salò. Nessa revista, aparece um artigo de Primo Levi, intitulado "Deportados. Aniversário".

Levi, naquele momento, "era ainda o autor de um livro semidesconhecido, que havia logo saído de circulação, lido somente por amigos, alguns militantes políticos e ex-deportados" (BELPOLITI, 2015, p. 187, tradução nossa). O artigo do "Prof. Levi", no número especial da revista Torino, configura-se como uma das primeiras intervenções públicas do autor e um dos primeiros artigos de opinião que escreveu. Se considerarmos o período que vai de outubro de 1945, data da volta para casa de Levi, até abril de 1955, data da exposição em Turim e da publicação do artigo citado, os escritos publicados de Levi resumiam-se ao Rapporto su Auschwitz - escrito na primavera de $1945 \mathrm{em}$ um dos campos de trânsito comandados pelo exército russo, em parceria com o amigo Leonardo De Benedetti - e ao testemunho das páginas de Se questo è un nomo que, inclusive, já tinham sido publicados esparsamente em periódicos ligados a associações de ex-deportados e a partidos de esquerda, dentre os quais o L'amico del popolo, do Partido Comunista de Vercelli, que publicou cinco textos que depois, um pouco modificados, fariam parte do livro de estreia do autor. 
O ano 1955 é também aquele no qual Primo Levi assina o contrato com a Einaudi para a publicação de Se questo è un uomo, fato decisivo para a sua carreira de escritor. O contrato foi assinado em julho daquele ano, três meses depois da publicação do texto sobre a deportação, e trata-se praticamente de um novo começo, ou propriamente do começo do itinerário literário, levando-se em consideração a pequena tiragem do volume lançado oito anos antes pela editora De Silva. A inserção da brevíssima experiência como partigiano na edição de 1958 - ausente naquela de 1947, que se iniciava com o relato da prisão no campo de Fossoli - é fruto da mudança do clima político e cultural que marcava o final dos anos 1950, momento no qual surgiam novos "locais" nos quais as discussões sobre o Lager e o genocídio puderam legitimar-se por meio de uma inesperada disposição em ouvi-las. Nesse terreno, surge um testemunho, aquele de Primo Levi, que vai muito além da Shoah, e reflete sobre os vários aspectos da condição humana.

Assim, sua trajetória literária foi ganhando forma. Os escritos e as reflexões de Levi, reconhecido inicialmente como um químico, ex-deportado e testemunha dos horrores da Segunda Guerra, foram lentamente e gradativamente ocupando espaço no ambiente cultural e intelectual italiano. Em 1958, após a reedição de seu livro de estreia pela editora Einaudi, que o havia recusado 10 anos antes, e a publicação de sua segunda obra, $A$ trégua, em 1963, o nome de Primo Levi era cada vez mais associado à literatura de testemunho, gênero crescente, sobretudo a partir dos anos 1960. A partir do final dos anos 1950, ficam mais frequentes suas aparições públicas e a contribuição com veículos de imprensa ligados, principalmente, a associações de ex-deportados e partidos de esquerda. Foi nessa época que passou a dedicar-se com especial empenho aos jovens, ao contato com outras gerações para que seu testemunho reverberasse e se tornasse conhecido, não se encerrando ali, mas tomando novas vozes. Frequentava escolas, proferia palestras, conversava com crianças 


\section{Primo Levi além da literatura: um intelectual engajado \\ Aislan Camargo Maciera \\ Helena Bressan Carminati}

e adolescentes, sempre num gesto de partilha e de desejo por diálogo. Além disso, começa a conceder entrevistas, tanto sobre sua experiência quanto sobre sua obra.

Ao lado dessa atividade crescente, que envolvia seu papel de escritor e testemunha, trabalhava na indústria química SIVA, uma fábrica de vernizes em Settimo Torinese, localidade nos arredores de Turim. Lá permaneceu, primeiro como técnico de laboratório, depois como diretor, até a aposentadoria em 1975, quando passou a se dedicar exclusivamente à carreira literária. Durante muito tempo, Levi considerou-se um "escritor de fim de semana", que se dedicava ao seu "segundo ofício" no tempo livre:

Eu sou dividido em duas metades. Uma é a da fábrica, sou um técnico, um químico. A outra, (...) é aquela na qual escrevo, respondo as entrevistas, trabalho sobre minhas experiências passadas e presentes. São exatamente dois meios cérebros (...). (LEVI, 2018, p. 17, tradução nossa)

Assim, ao longo de seu caminho, sempre esteve dividido entre a atividade literária, à qual dedicava-se pontualmente, e seu ofício como químico que tomava a maior parte de seu tempo. O ano de 1975 marca a aposentadoria de Levi da SIVA, e também o lançamento de $A$ tabela periódica, obra que seria responsável, na década seguinte, pela definitiva inserção do autor no cânone da literatura ocidental da segunda metade do século XX ${ }^{1}$. Naquele momento, Primo Levi, judeu, laico, ex-deportado e sobrevivente dos campos de concentração, químico, escritor da literatura de testemunho e de ficçãocientífica - naquele período já tinha publicado dois volumes de contos -, admite para si um outro papel, o qual iria desempenhar até o último dia de sua vida e talvez já o viesse fazendo, ainda que inconscientemente.

Passa a contribuir assiduamente com jornais e periódicos de alcance nacional, tornando-se colaborador permanente do La stampa, cotidiano de Turim, e um dos mais importantes jornais italianos. Consolida-se, portanto, como intelectual engajado, voz a ser ouvida acerca de diversos temas, que iam 
muito além das histórias sobre a Segunda Guerra e sobre o Lager. É nesse momento que Levi passa a escrever sobre as coisas do mundo que indiretamente tocavam a sua experiência no Campo, mas que iam muito além dela, chegando ao presente e às questões efervescentes da época.

No Brasil, seus escritos chegaram no final da década de 1980, após a sua morte. Visto também aqui, predominantemente como escritor-testemunha, somente em tempos mais recentes a face poliédrica de sua obra começou a ser desvendada e revelada. A sua obra ensaística, aquela que explicita sua face de intelectual engajado, chegou ao público brasileiro recentemente, em duas publicações, ambas de 2016 e publicadas pela editora da Unesp.

O primeiro volume é a coletânea de artigos $O$ ofício alheio, originalmente publicado em 1985, e que apresenta textos que Levi escreveu para jornais e revistas, sobretudo o La Stampa. Quase todos os textos foram escritos entre 1976 e 1984, com a exceção de dois, escritos em 1964 e 1965. O segundo volume é $A$ assimetria e a vida: artigos e ensaios 1955-1987, a tradução de um livro publicado postumamente na Itália, em 2002, e organizado por Marco Belpoliti. Trata-se de uma reunião de artigos em duas obras que apresentam uma variedade de temas e conteúdos, e que foram escritos do período que vai do pós-guerra até o ano de sua morte, 1987. É importante ressaltar que alguns artigos presentes em $A$ assimetria e a vida foram publicados no La Stampa e depois reunidos em um volume intitulado Racconti e saggi ${ }^{2}$, o último livro publicado por Levi em vida, no outono de 1986, poucos meses após o lançamento de Os afogados e os sobreviventes.

Os artigos reunidos nesses volumes trazem uma diversidade de assuntos que interessavam a Levi: desde o Lager - trazido muitas vezes de forma implícita - passando por temas ligados às ciências naturais, à zoologia, à astronomia, e chegando às considerações sobre a escrita, o estilo e a tradução literária. Também são discutidas as questões que estavam na ordem do cotidiano naquele 
momento, tais como a intolerância racial, o fanatismo "religioso", a violência, os regimes ditatoriais e totalitários.

Nesse sentido, ambas as obras carregam um importante compilado dos artigos e ensaios publicados ao longo da vida de Levi, expressando muitos dos pensamentos encontrados em suas páginas literárias, agora apresentados de outra forma. Assim, ao perpassar por esse hibridismo que é parte fundamental da obra primoleviana, o que nos chama a atenção é o fato de Levi sustentar para além de sua prosa e poesia - estendendo-se a artigos, ensaios e entrevistas - um engajamento e um empenho por questões que certamente não estão dissociadas da experiência como prisioneiro, mas que acabam extrapolando-a. $O$ fato de não ter se restringido apenas à literatura, mas ter ocupado espaços, podemos dizer, mais populares, como jornais e revistas, é também um indício daquilo que ele, não apenas como sobrevivente da Shoah, se propôs a fazer ao longo da vida.

Com o passar dos anos, sua literatura foi sendo reconhecida, como já dito, a passos lentos: por muito tempo foi um químico que nas horas livres, dedicavase à escrita. Sua trajetória não esteve circundada por grandes círculos literários, tampouco cercada por escritores ou intelectuais. Levi, inclusive, mantinha poucas relações que provinham desse ambiente, como o caso da amizade com o escritor Italo Calvino, de quem foi bastante próximo e profundo admirador. Desse modo, é como se a circunstância que o fizera escritor, o campo de concentração, o restringisse de certa forma do contato com grande parte do mundo intelectual e literário italiano, do qual demoradamente foi se aproximando.

Ao pensarmos, então, no contexto em que estava inserido e no qual trilhou seu caminho como um ex-deportado que se tornara escritor, a atividade de articulista e ensaísta da imprensa nos parece bastante representativa. Sobrevivente de Auschwitz e escritor, Levi nutria um desejo por elaborar e refletir sobre a condição humana. Com uma escrita objetiva, que vinha muito 
de seu trabalho com a química, era um atento observador dos ambientes e das pessoas, o que o levou a ser um escritor empenhado, principalmente, em comunicar-se com o leitor. Como ele mesmo dizia: "um texto tem muito mais valor, e muito mais esperança de ser difundido e se tornar eterno, quanto melhor for compreendido e quanto menos se prestar a interpretações equívocas" (LEVI, 2016b, p. 56).

Daí, talvez, o ato de ser colaborador do La Stampa e de outros grandes jornais italianos como um modo, para além da literatura, de expor suas ideias e mostrar-se como um escritor para além das páginas literárias. Durante os anos em que se dedicou a essa atividade escreveu, como vimos, sobre diversos temas. Apresentava um olhar muito cauteloso e ao mesmo tempo objetivo, característica de estilo evidente desde suas primeiras narrativas. A preocupação com as questões sociais, que se tornou latente após sua experiência no Lager, foi o ponto de partida para a sensibilidade com que enxergava e escrevia sobre o mundo.

Atravessado pelo olhar analítico, quesito essencial para um químico, Levi escreveu sobre muitas das questões que ainda hoje tomam nosso cotidiano. Italo Calvino, no prefácio de $O$ ofício alheio, afirma que o escritor piemontês possuía uma "vocação de enciclopedista das curiosidades vivazes e minuciosas, e de moralista de uma moral que parte sempre das observações" (LEVI, 2016b, p. VII). Figura frequente da chamada "Terza pagina" de importantes veículos da imprensa italiana, Levi parecia atingir aquele intuito que estava na origem de seu fazer literário. Desejava, desde o princípio de sua aventura como escritor, que um público cada vez maior pudesse ouvir a sua voz, tanto como testemunha da história, quanto como intelectual que, através de sua experiência, tinha tanto a dizer sobre as questões contemporâneas.

Dentre os assuntos sobre os quais Levi era convidado a debater, seja através dos artigos, seja em suas entrevistas - também cada vez mais frequentes 
a partir do final da década de 1970 - estava a questão da intolerância racial, pilar fundamental da ideologia e da política hitlerista na Alemanha do III Reich. Por razões óbvias, a perseguição a determinados grupos étnicos e os genocídios da história chamavam a atenção do autor, que viu de perto a chamada "solução final" e os campos de concentração e extermínio. O tema, naquele momento extremamente relevante para o autor, fora relevante em outros tempos históricos anteriores a ele e, pelo que se nota, ainda está entre os mais urgentes do século XXI.

No final da década de 1970, a prefeitura de Turim organizou uma série de encontros com intelectuais da cidade, que foram responsáveis por algumas conferências que abordavam assuntos ligados à história e à contemporaneidade. Em novembro de 1979, Primo Levi proferiu a conferência "Intolerância racial", texto que se transformou em um breve ensaio, publicado pela primeira vez na primeira edição das obras completas do autor, em 1997, e depois no volume $A$ assimetria e a vida, ambos organizados por Marco Belpoliti. A conferência, utilizando exemplos históricos e biológicos, pautados pela ciência, reflete sobre os conflitos gerados pelas diferenças "raciais" e sobre a aversão que alguns povos nutrem contra outros. Em uma chave interpretativa que remonta a uma natureza pré-humana do fenômeno, Levi afirma que "a aversão, esse obscuro instinto que impele os homens a se reconhecerem diferentes entre si, tem raízes muito antigas" (LEVI, 2016a, p. 179).

Evidentemente, uma das perguntas mais dirigidas ao autor ao longo de sua carreira como escritor tratava-se do antissemitismo. Quando questionado, Levi fazia questão de aproximar o ódio aos judeus a outras diversas representações análogas de ódio racial ao longo da história humana, e que igualmente produziram massacres e genocídios. Ao tratar do tema, sempre de forma clara e didática, expõe a intolerância racial como uma espécie de patologia, vinda de uma natureza biológica, que só poderia ser freada pelo "acionamento das 
faculdades racionais" (BASEVI, 2019, p. 259). Mas, ao mesmo tempo, não ignora a influência dos processos históricos, sociais e culturais para a geração do ódio entre as "raças". Citando outros grandes exemplos da história, nos quais povos inteiros foram dizimados em nome de uma superioridade racial e cultural - os indígenas da América, os aborígenes australianos e os povos africanos, escravizados por séculos pelos europeus -, o autor reflete sobre um fenômeno ainda presente em discursos de ódio proferidos, por exemplo, pelos políticos da extrema-direita europeia que hoje levantam bandeiras antimigração, incitando a violência contra determinados grupos étnicos.

Anos depois da conferência, mais precisamente em 1985, Levi seria entrevistado pelo jornalista Marco d'Eramo, escritor e ensaísta, que naquele momento trazia as palavras de Levi sobre um tema ainda relevante no contexto social e político: o racismo. A entrevista, publicada originalmente na seção "La talpa libri" do cotidiano comunista Il Manifesto em 5 de setembro de 1985, é apresentada em português, pela primeira vez traduzida ao leitor brasileiro:

\section{Primo Levi: o racismo volta nu e cru, por Marco d'Eramo}

Primo Levi, no que o racismo se transformou, segundo o senhor, nos últimos cinquenta anos?

Ele se purificou, se me é permitido usar um termo tão cínico. Se purificou retornando às suas origens. A explosão do racismo que culminou no antissemitismo de Hitler deu seus frutos, se propagou. Com a Segunda Guerra Mundial e com o hitlerismo, o antissemitismo havia perdido boa parte do seu caráter de luta religiosa para transformar-se em puro ódio racial. E assim permaneceu, e levou ao explodir, em vários cantos do mundo, de um racismo no sentido estrito do termo, isto é, "aversão pelo diferente". Aconteceu na 
segunda metade dos anos quarenta nos Estados Unidos, aconteceu na França, na Europa. Depois da Segunda Guerra Mundial, o racismo perdeu aquela espécie de aura racionalizada que havia sempre sustentado para voltar aos seus fins originais de hostilidade devida à diferença.

Em particular, o antissemitismo: percebeu transformações ou ele sempre teve as mesmas características?

$\mathrm{O}$ antissemitismo é um Proteu ${ }^{3}$. Muitas vezes, com o passar do tempo, ao longo dos anos, mudou sua terminologia. Mas, até o nosso século, o antissemitismo estava camuflado por questões religiosas. Os judeus eram os não crentes. O judeu convertido, em teoria, deveria deixar de ser judeu. $\mathrm{Na}$ realidade, no século XVI, na Espanha, os judeus convertidos não deixaram de ser judeus. Mesmo depois da conversão, mais ou menos forçada, continuaram a ser suspeitos. O termo marrano ${ }^{4}$, isto é, judeu convertido, era um insulto.

No entanto, há uma história trágica: justamente entre as vítimas do racismo, entre os judeus do Estado de Israel, parecem reaparecer formas de racismo, não apenas contra os árabes (racismo externo), mas também formas de racismo interno, contra os falascià ${ }^{4}$ os judeus etípes em primeiro lugar, mas também entre os asquenazis e sefarditas. Como explicar esse esquecimento que consente fazer aquilo do qual um dia se foi vítima?

Deixarei de lado o discurso sobre os falascià porque é complexo e porque foi um episódio esporádico, logo passou. Que existam em Israel germes de racismo, infelizmente, é verdade. O racismo acompanha, como sintoma, as patologias mais complexas. Ora, Israel está em crise: crise econômica, crise política, crise de identidade. Essa crise vem acompanhada por uma ruptura interna, inclusive política, devido à diversidade manifesta entre os fundadores do estado de Israel, que eram de origem polonesa, russa, centro-europeia, e de “outros", judeus provenientes do norte da África e do Oriente Médio, que são vistos como intrusos, como gente protegida, gente ajudada que não é suficientemente agradecida. Existem tensões. No fundo, diria que se trata ainda 
e sempre do fato zoológico, diria zootécnico, do ódio pelo diferente. Mas tenho a impressão de que seja um fenômeno transitório, destinado a atenuar-se. Ao menos, assim espero. Seria realmente um impedimento a própria ideia de um estado de Israel, se tais coisas continuassem.

Passemos à Itália. Há uma forma de racismo entre setentrionais e meridionais, que se intensificou com a revolução industrial. Como evoluiu esse racismo?

Tenho a impressão de que esteja rapidamente atenuando-se. Por razões óbvias: falta a matéria. Em primeiro lugar, um bom número de emigrados da Itália meridional está voltando às suas cidades de origem. Quem ficou, foi assimilado. As diferenças eram extremamente tênues. A principal diferença consistia no sotaque. É curioso, no Piemonte onde vivo, o "terrone" é identificado, sobretudo, pelo seu sotaque. Quando o perde, não é mais Outro. E o perde rapidamente, em uma geração, ou talvez nem tanto. Os filhos vão à escola e se vê o nascimento de um sotaque novo que não é mais piemontês, não é mais meridional, é uma koinè dialektos, e não suscita tensões.

O atenuar-se do racismo norte-sul não é devido também à presença de "verdadeiros africanos", "verdadeiros árabes", sobre os quais se descarrega um racismo comum de meridionais e setentrionais?

Pode ser que exista esse fenômeno, mas é minoritário. Quantos são os verdadeiros árabes? Serão 20000, talvez nem isso...

As últimas estimativas falam, entre imigraşão oficial e imigração clandestina, entre árabes, africanos, filipinos, em cerca de um milhão de imigrantes.

Um milhão de pessoas? Não conheço o fenômeno, e não saberia discutilo. Não me parece que seja acompanhado de uma onda agressiva. Suscitam comiseração e, também, desprezo, mas ódio mesmo, não. Também, em parte, porque são trabalhadores domésticos, são elementos marginais, têm um pequeno comércio nas praias e nos hospitais, vendem tapetes. Não são vistos como invasores e rivais. Se servem para reagrupar a unidade nacional, do meu 
ponto de observação não o enxerguei, parece-me que a sua presença seja ainda insuficiente.

Uma última pergunta. Entre as suas experiências pessoais de racismo, qual o marcou mais?

Sem dúvidas, o desencadeamento, não no âmbito governamental, mas a nível de base, do ódio na Alemanha nazista. Nos últimos meses de prisão em Auschwitz, próximo ao nosso Lager, aliás, ao canteiro onde trabalhávamos, havia um acampamento da Hitlerjugend'. Eram adolescentes, como os Avanguardisti italianos, jovens de 14-15 anos. Os seus líderes, que eram veteranos das SS, os acompanhavam para nos ver, em visita guiada. Acompanhavam-lhes no canteiro bombardeado onde estávamos nós, prisioneiros, quase todos judeus, que recolhiam os destroços. E como se nós não ouvíssemos, explicavam-lhes, muito objetivamente, muito friamente: "Vejam, esses são os inimigos do nosso país. Nós os tornamos inofensivos. Colaboram como podem, limpando os destroços, sendo lixeiros. Mas, como veem, são brutos, não tomam banho, não sabem nem mesmo falar alemão, não se barbeiam. É justo o que fazemos com eles: torná-los inofensivos. Não são seres humanos, o veem com seus próprios olhos". Isso me fez tocar com as mãos como o ódio racial, em sua encarnação mais cruel, possa ser fortalecido, usado e explorado.

\section{Considerações finais}

Marco d'Eramo indaga Levi sobre um assunto de extrema relevância e atualidade social e política, a questão racial. Durante a conversa, entrevistador e entrevistado não fazem nenhuma referência às obras de Levi, naquele momento, já renomado e premiado escritor. A ausência de tais referências faz com que destaquemos dois pontos: o primeiro é que Levi havia se consolidado 


\section{Primo Levi além da literatura: um intelectual engajado \\ Aislan Camargo Maciera \\ Helena Bressan Carminati}

como escritor, o que dispensava a necessidade da conversa explicitar referências à sua obra; o segundo é que, a partir dessa constatação, fica evidente que mais uma face da poliédrica personalidade intelectual do autor estava igualmente consolidada. Levi era uma voz a ser ouvida no debate das questões contemporâneas.

As respostas dadas pelo escritor apesar de não serem ampla e profundamente discutidas, manifestam características pertencentes ao seu modo de colocar-se no mundo. Usando de uma fina ironia, recurso muito presente em seus escritos (como quando diz que o racismo havia "se purificado") e expressões cautelosas como, "se me é permitido", "tenho a impressão", "do meu ponto de observação", Levi expõe uma de suas grandes virtudes: a capacidade de observação e a exposição de suas reflexões e posicionamentos de forma serena, porém, incisiva, clara. Levi fala com propriedade. Propriedade de quem sabe, a partir da própria experiência, o que é a intolerância racial e o racismo; propriedade de um químico, ligado aos preceitos das ciências naturais, que chamavam a sua atenção desde a infância e adolescência; propriedade de quem analisa os acontecimentos históricos, e observa a seu redor a iminente ameaça de retorno dos totalitarismos e potenciais genocídios.

Ao ser questionado sobre a transformação do racismo ao longo dos anos, Levi traz reflexões sobre as representações de intolerância presentes naqueles tempos. As considerações que faz, assustadoramente, encontram ressonância nos contextos políticos e ideológicos deste nosso século: atritos gerados pela intolerância, pela incapacidade de se conviver com a diferença que alimentam os discursos de ódio propagados aos quatro ventos por uma extrema-direita sedenta pelo poder. Afinando seu discurso com os seus potenciais eleitores, agitam bandeiras nacionalistas, anti-imigração, depositando no estrangeiro, no 
diferente, a culpa pelos fracassos do Estado liberal sob a égide do capitalismo de mercado.

Dessa forma, não é somente a literatura de Primo Levi - com seu estilo claro, racional e conciso - a se configurar como importante ferramenta de diálogo com o nosso tempo. Sem sombras de dúvida, tanto sua obra testemunhal, quanto sua ficção, são fontes de experiências e reflexões, e tornam-se fundamentais como matéria de discussão de temas atuais. Porém, esta outra face do autor, menos difundida e conhecida traz, com a mesma clareza e racionalidade, subsídios que alimentam o debate sobre temas, ao mesmo tempo, atuais e urgentes. O poliedro Primo Levi, italiano de origem judaica, químico, deportado, sobrevivente, testemunha, escritor, é também o intelectual engajado, que se assume como um enciclopedista, indagando sobre problemas linguísticos, etológicos e comportamentais, e transformando-se em uma voz que precisa ser ouvida.

\section{Referências}

BASEVI, Anna. Bárbaro, inimigo, amigo: o estrangeiro entre a construção política e a narrativa de testemunho. Alea: Estudos Neolatinos, 21/2, 2019, p. 255-272.

BELPOLITI, Marco. Primo Levi di fronte e diprofilo. Milano: Ugo Guanda Editore, 2015.

LEVI, Primo. A assimetria e a vida: artigos e ensaios 1955-1987. Tradução de Ivone Benedetti. São Paulo: Editora Unesp, 2016a.

Unesp, 2016b.

O ofício alheio. Tradução de Silvia Massimini Felix. São Paulo: Editora

. Opere complete III: conversażioni, interviste, dichiaraz̧ioni. Organização de Marco Belpoliti. Torino: Einaudi, 2018.

Notas 


\section{Primo Levi além da literatura: um intelectual engajado \\ Aislan Camargo Maciera \\ Helena Bressan Carminati}

${ }^{1}$ No final de 1984, a editora Shocken Books lançava nos Estados Unidos a tradução em inglês, feita por Raymond Rosenthal, de $A$ tabela periódica. O lançamento suscitou entusiasmadas resenhas críticas, dentre as quais a que ganhou mais destaque foi a do escritor Saul Bellow. Apesar de ter alguns de seus livros já traduzidos para o público de língua inglesa - If this a man (1959) e The truce (1965) -, foi somente com a publicação de The periodic table que Levi conquistou definitivamente seu espaço no debate cultural anglófono, fato que impulsionou a recepção de seus escritos pelo mundo. A obra foi considerada pelo NY Times Book Review um dos melhores livros de 1985, e chamou a atenção também da comunidade científica.

${ }^{2}$ Racconti e saggi - edição sem tradução para o português, conta com 15 contos e 20 ensaios, todos originalmente publicados pelo autor no La Stampa, em uma coleção de livros editada pelo jornal e intitulada "Terza Pagina". Os contos seriam reunidos em um volume póstumo, publicado pela Einaudi, e intitulado L'ultimo Natale di guerra (O último Natal de Guerra, traduzido no Brasil e publicado pela editora Berlendis \& Vertecchia, em 2002); os artigos, posteriormente, fariam parte de $A$ assimetria e a vida.

${ }^{3}$ Deus da mitologia grega, habitante dos mares, da terra, dos rios, com capacidade de mutação.

4 Termo injurioso que designava, genericamente, na Península Ibérica, os judeus convertidos, mas que ainda eram suspeitos de serem fiéis ao judaísmo.

${ }^{5}$ Povo de origem etíope e fé judaica.

${ }^{6}$ Termo preconceituoso e depreciativo para o italiano do sul.

7 Juventude hitlerista. 